\title{
A modo de presentación. Apuntes sobre la literatura de viajes
}

\author{
Gisela Galassi \\ UNR-CESOR-ISHIR/CONICET \\ María Soledad Lollo \\ UNR-CESOR-ISHIR
}

Desde hace unas dos décadas, desde las Ciencias Sociales y Humanidades, se converge en nuevos estudios y "miradas", en la escritura y la narrativa como núcleos que condensan perspectivas teóricas y epistemológicas insoslayables sobre la problemática del viaje y la literatura de viajeros. La transposición de la experiencia de viaje por medio de una narración, un discurso o un relato de viaje se constituye en problema per se a la vez que llega de diferente manera a públicos diversos. Esta "audiencia" cambia con el tiempo y el espacio aunque siempre será susceptible de ser impactada por la narración viajera. Pero un relato de viaje además de diferenciarse por su forma, por su cadencia de escritura, lo hará también por la marca en esa escritura de un eje sobre el cual se estructura el relato. De este modo, en los siglos XIV y XV, los viajeros dibujaron la imagen del mundo y trazaron los límites de lo "mismo" y de lo "otro"; en el siglo XVIII, el viaje es la clave para la adquisición de conocimientos nuevos y la constitución y desarrollo de la ciencias en la modernidad, ${ }^{1}$ en el XIX atravesaron las fronteras para asegurarlas mejor; para que en el XX resultara difícil determinar quiénes eran los unos y los otros en la multiplicación que supuso la inmensidad del "espacio exterior", la inconmensurabilidad del "hiperespacio", la indeterminación del "espacio virtual" y la denegación de la frontera (política) a través de la metáfora de la "globalidad". Los relatos de viaje del siglo XX celebraron, entonces, una particular relación con el tiempo y con el espacio que es la transitoriedad; en su doble acepción que designa un movimiento - cierta forma de circulación- y una temporalidad provisional.

1 En la Encyclopédie el artículo "Voyages” afirma: “... los viajes amplían el espíritu, lo elevan, lo enriquecen de conocimiento, lo curan de prejuicios racionales...su objeto principal es examinar las costumbres, el genio de las otras naciones, su gusto dominante, su arte, su ciencia, su manufactura y su conocimiento...".

GALASSI, Gisela y LOLLO, María Soledad, “A modo de presentación. Apuntes sobre la literatura de viajes” en Avances del Cesor, Año VIII, N 8, 2011, pp. 83-89. 
En consecuencia, el relato y la literatura de viajes ofrece en nuestros días un amplio campo de análisis y la posibilidad de aplicar en él distintos marcos teóricos ${ }^{2}$ asentados desde una perspectiva interdisciplinar que alienta a cruzar las fronteras específicamente históricas y estudiarlos como objetos privilegiados de análisis. Prueba de ello es el número de encuentros y publicaciones que lo tienen por materia de estudio, y se extiende cada vez más el interés por su conocimiento.

Este Dossier que tenemos el agrado de presentar, reúne originales contribuciones dedicadas a estas temáticas. Espacio, identidad, alteridad, discurso, colonización, son algunos de los núcleos conceptuales que ocupan y unen la secuencia argumentativa que entretejen los mismos. Cada uno tiene una historia particular y segmentaria. Pero todos se enmarcan en el complejo proceso que se inició una vez que el hombre europeo llegó a América.

El descubrimiento de América incitó tanto la realización ulterior de un sinnúmero de expediciones como el inicio de una zaga de literatura de viajes que, desde entonces, signó la historia de las cuatro partes del mundo. ${ }^{3}$ Cuando Cristóbal Colón escribió los diarios de sus cuatro viajes estaba convencido de que había llegado a Asia. Murió sin saber que la tierra que había hallado era un nuevo continente y nunca se rindió ante las evidencias que le indicaban, una y otra vez, que no estaba donde presumía. América aún no había sido "inventada" por los navegantes, la Corona, y los teóricos del siglo $\mathrm{XVI}^{4}$ pero ya contaba con relatos de viajeros.

2 Desde distintas disciplinas se lo ha estudiado haciendo énfasis en su perspectiva documental, histórica, etnográfica y estética. En los últimos años, desde la literatura y los estudios culturales se ha puesto el acento en definir como la literatura de viajes producida por escritores europeos y americanos participaron en la fundamentación epistemológica del colonialismo y el imperialismo. Véase, PRATT, Mary Louise, Ojos imperiales, Literatura de viajes y transculturación, Fondo de Cultura Económica, Buenos Aires, [1997] 2011.

3 El relato de viajes conforma un extenso corpus, que puede afiliar, tanto a memorias, crónicas, informes de funcionarios, así como también relatos propiamente literarios colocados bajo el signo de la ficción. Sofía Carrizo Rueda ha definido claramente la hibridez de estos relatos en donde lo documental y lo literario se articulan sin perder nunca su primaria definición: el itinerario es el protagonista principal y regula la funcionalidad de todos los otros elementos y configura el discurso. CARRIZO RUEDA, Sofía, Escrituras del viaje. Construcción y recepción de 'fragmentos de mundo', Biblos, Buenos Aires, 2008. Para una lectura interesada en la definición de la escritura del viaje y los procesos culturales que la atraviesan, se pueden mencionar las siguientes obras que no se agotan en una oferta mucho más amplia; MONTELEONE, Jorge, El relato de viaje, Buenos Aires, 1998; FERRONE, Vincenzo y ROCHE, Daniel (editores.) Diccionario Histórico de la Ilustración (apartado Viajes), Alianza, Madrid, 1998; PRATT, Mary Louise, Ojos imperiales..., Op. Cit.; FERNÁNDEZ, Sandra, GELI, Patricio, y PIERINI, Margarita (Editores), Derroteros del viaje en la cultura: mito, historia y discurso, Prohistoria Ediciones, Rosario, 2008.

4 O'GORMAN, Edmundo, La invención de América, Fondo de Cultura Económica, México, [1958] 1976. 
Los diarios de viaje del almirante evidenciaban sus expectativas y creencias pues, cuando éstas no se condecían con los hallazgos, su consecución se presentaba como una promesa para una instancia ulterior del viaje. En esta actitud de Colón, además de un intento de legitimar su empresa, encontramos huellas de la concepción que hasta ese momento se tenía respecto de los viajeros. Desde tiempos tan remotos como los de La Odisea, los viajeros no gozaban de una buena reputación. Más bien se los calificaba como impostores y mentirosos. A sus relatos no se les exigía la veracidad; al contrario, se les otorgaba la licencia de apelar tanto a la exageración como a la imaginación como compensación por haberse trasladado hasta sitios tan distantes: "La mentira, o si se prefiere 'el embellecimiento', era y sigue siendo el derecho, el privilegio de todo viajero y de todo historiador en tanto que autores, algo así como el justo botín de los ladrones esforzados". ${ }^{5}$ Los relatos se condecían con lo que el público esperaba de ellos. Pero la situación cambiaría con los viajes a América y, más tarde, el ascenso del empirismo como criterio de autoridad.

El nuevo mundo se convirtió en el escenario donde los europeos proyectaron sus utopías, sus mitos y sus fantasías y, en el intento de recrearlos, se transformaron a sí mismos. El Dorado, La Ciudad de los Césares, la ciudad de Cíbola y la ciudad de Quivira, entre otros mitos, alentaron las empresas de descubrimiento que irrumpieron en el continente a lo largo del siglo XVI. El reconocimiento de las costas, el afán por circunnavegar el globo y la búsqueda del paso a Asia por el estrecho de Bering, incitaron las expediciones marítimas. Españoles, franceses, holandeses, ingleses, cada uno en su momento, se lanzaron a una expansión incontenible y desafiante, en donde aparecían nuevos "otros", nuevos horizontes, nuevas perspectivas, "nuevos mundos", plenos de misterio y de pasos extraños; tomando el cariz de un presente inquietante e intranquilizador que debía ser conocido, transitado y finalmente medido y domesticado.

Los primeros cronistas y visitadores de la América Española fueron los viajeros del siglo XVI. La dominación europea, estaba allí, inapelable e ineludible, avanzando a través de párrocos, exploradores o funcionarios; viajeros en suma de distinta naturaleza y propósitos. Cada cual a su modo y fieles a su cometido procuraron sistematizar las noticias sobre las posesiones americanas dando lugar a reportes de información de distinto tipo. Los escritos de Fray Bartolomé de las Casas y Bernal Díaz del Castillo cumplieron, si se quiere de un modo más literario -aunque no por ello exento de intencionalidad política- este cometido. Además, los informes para las autoridades metropolitanas bajo el formato de encuestas y, más tarde, de cuestionarios que desde el Consejo de Indias les proveyeron a los distintos agentes, contribuyeron en el mismo sentido. Estos últimos dispositivos funcionaron como patrones para la recolección de datos y revistieron un carácter claramente descriptivo cuyos temas oscilaban entre los recursos del nuevo continente, la caída demográfica, la geografía,

5 PIMENTEL, Juan, Testigos del mundo. Ciencia, literatura y viajes en la ilustración, Marcial Pons Editora, Madrid, 2003, p. 36. 
las culturas indígenas o las cuestiones de la Real Hacienda, según el momento en que fueron diseñados. Las Ordenanzas del Consejo de Indias (1571) promulgadas durante la gestión de Juan de Ovando indican sobre las materias que debían ser informadas, ajustándose a los principios de la Historia Natural y Moral y señalando un marcado interés por el conocimiento del otro. ${ }^{6}$ Así pues, desde el siglo XVI, las informaciones procedentes de ultramar sirvieron a los intereses de la Corona pues era menester ordenar y organizar los saberes sobre sus posesiones americanas.

Las expediciones marítimas no se quedaron atrás a la hora de reconocer, descubrir y explorar las superficies aún ignotas del planeta y los pasos que habrían de interconectar el mundo conocido. Los españoles, más preocupados por sostener y defender su imperio que por aventurarse a nuevas conquistas, se interesaron inicialmente por esta empresa-de hecho, hallaron e intentaron poblar el Estrecho de Magallanes- pero, en siglo XVII, relegaron casi completamente esta ambición. Fueron los franceses e ingleses quienes llevaron la delantera en esta carrera: el pirata Francisco Drake (1577), el Capitán Narburugh (1670), Monsieur Bauchene-Govi (1698), Wodes Rogers (1708), Monsieur Amadée Frezier (1711) y Jorge Anson (1740), son los casos más representativos.

La connotación del viaje, el viajero y sus relatos cambiaría radicalmente en el siglo de la ilustración. El viaje, se convierte en una forma de empresa educativa, geográfica y literaria, dando lugar a una literatura de viajeros, con un discurso y recursos diferenciados que sirvieron para plasmar esa experiencia. El viaje en el siglo de las luces, se trasforma en objeto de reflexión y deviene en una de las formas que adquiere el conocimiento, una forma de desplazamiento en el espacio, una "practica" del espacio. Los grandes viajes aparecen vinculados a la figura del peregrino laico y del peregrinaje como producción de saber. Los exploradores tienen como misión conocer lo que no se conoce, producir un nuevo conocimiento. La fuerza propulsora del movimiento ilustrado, respondió a la utilidad del saber y su propósito fue conciliar: "comercio, ciencia y progreso". ${ }^{7}$ Los reformistas ilustrados encontraron en América el laboratorio que, por excelencia, contribuiría al desarrollo de la ciencia y al mismo tiempo a re situar a la Monarquía Hispánica a la altura de sus pares europeas. En este sentido, no podemos dejar de mencionar la expedición francoespañola encabezada por el geógrafo Charles de la Condamine que pretendía determinar de una vez y para siempre la forma exacta de la superficie de la tierra. A ésta le siguieron otras cuyo común denominador fue aportar conocimiento útil a la Corona: Hipólito Ruiz y José Pavón se trasladaron hasta Chile y Perú para reconocer nuevas especies de plantas; José Celestino

6 ALTUNA, Elena, El discurso colonialista de los caminantes. Siglos XVII y XVIII, Latinoamérica Editores, California, 2002.

7 BOURGUET, Marie Nöelle, "Voyages et Voyageurs" en Dictionnaire Européen Des Lumierés (sous la Direction de Michel Delon), París, P.U.F., 1997, pp. 1092 y ss. 
Mutis se dirigió al Virreinato de Nueva Granada; Martín Sessé visitó Nueva España, Alejandro Malaspina recorrió las colonias asiáticas y americanas.

La modernidad abrió la aventura de viajar a "científicos heroicos", naturalistas, mercaderes y diplomáticos que sumieron las páginas y los derroteros de los libros de viaje. El contacto directo con los hechos naturales -que por insólitos no resignaban su carácter científico- fue la llave que permitió que los viajeros adquirieran una nueva reputación. El reflejo de su auténtico saber en la escritura los emplazó como testigos del mundo: “... si el mandato de la ciencia moderna era leer directamente en el Libro de la Naturaleza, había que aprender a hacerlo, había que sistematizar esa práctica que consistía en viajar observando, recolectando y describiendo hechos naturales, una práctica muy antigua pero que ahora, en virtud de las mencionadas novedades, se revelaba como una práctica fundamental para hacer y difundir conocimiento natural." $"$

Al mismo tiempo que convidaba a sus ávidos lectores con textos de aventuras, mediciones e "inventarios", el viaje y su conversión en escritura, se constituyeron en una empresa intelectual y política de reconocida utilidad pública por parte de élites europeas, inclinadas a redefinir su entorno natural y humano. En consecuencia, esto se evidenció en el despliegue de una variada gama de operaciones intelectuales, políticas y económicas que en el contexto de la política ilustrada dio lugar a la concreción de las mencionadas expediciones científicas, impresión de obras eruditas, creación de academias y la conformación de jardines botánicos.

Las investigaciones sobre viajes y viajeros se han realizado haciendo especial énfasis, por un lado, en el carácter celebratorio de los relatos de viajes, recapitulando las hazañas de intrépidos o abnegados viajeros, descubridores de nuevos espacios, ríos, especies vegetales y animales. Acentuando la relación intrínseca del viaje con la historia del descubrimiento y la colonización de nuevos espacios, el viajero aparece como el precursor de la expansión europea en el mundo, como antecesor de las conquistas militares europeas, de la conquista material y luego intelectual.

8 PIMENTEL, Juan, Testigos del mundo..., Op. Cit., p. 52. Cabe destacar la estrecha relación que, para este período, se establece entre viaje y ciencia y una cuyas manifestaciones es la institucionalización del estudio de la historia de la ciencia. Durante el siglo de la ilustración, los saberes y prácticas científicas europeos implicaron una movilización de personas, instrumentos y teoría que, una vez en América, se imbricaron con las distintas realidades locales. Como se ha señalado: "Antes de ser reconocida universalmente, la ciencia ocurre localmente, del mismo modo, los instrumentos científicos son accionados en contextos y arreglos locales, y sólo bajo el intenso proceso de desplazamiento o des-localización del lugar donde fueron creados, algunos se convierten en parte de una empresa global." Véase: BOURGUET, Marie Nöelle, LICOPPE, Christian, SIBUM, H. Otto, Instruments, Travel and Science: Itineraries of Precision from the Seventeenth to the Twentieth Century, Routledge, 2003. Citado en CHAZARO, Laura La cultura médica instrumental: los viajes políticos de los esfigmógrafos entre Europa y América, Nuevo Mundo Nuevos Mundos, México, 2007, http:// nuevomundo.revues.org/3092?lang=en\#ftn26 
Como ya se ha mencionado, en los últimos años, se ha superado ampliamente esta postura, dando lugar a toda una serie de trabajos y argumentaciones que desarrollan una mirada crítica de la literatura de viajeros, revisando su tradicional tratamiento como fuentes históricas primarias, deteniéndose en el análisis del contenido del relato, las especificidades como género literario y las razones y formas de su publicación.

En consecuencia, Rogelio Paredes en Guerra en los libros. La competencia colonial del siglo XVIII entre Gran Bretaña y Francia...., pone de manifiesto la doble confrontación militar y editorial de estas potencias, sobre la base de los libros de viaje existentes en la biblioteca del Museo Etnográfico de Buenos Aires. Así, “... el estudio no sólo procura documentar en el plano intelectual, científico y editorial la competencia diplomática y militar entre los colonialismos británico y francés, sino también indagar en la importancia de la difusión bibliográfica como instrumento de propaganda de sus objetivos coloniales y de incorporación de los intereses del público lector a la empresa de expansión comercial y territorial en ultramar".

Por otra parte, el artículo de Carolina Martínez: Definición, apropiación y construcción del espacio en la Tierra Austral Incógnita, estudia el papel que este concepto ocupo “... en tanto espacio geográfico pero también tópico en la literatura de viaje europea de la primera modernidad jugando un papel de singular importancia en la Francia de mediados del siglo XVII, al cumplir con la doble función de justificar la expansión ultramarina y a su vez convertirse en depositaria de las múltiples sociedades imaginarias que en esta época se concibieron". Desde esta perspectiva y partiendo desde sus remotos orígenes hasta avanzado el siglo XVIII, indaga los usos y el lugar ocupado por la tierra austral incógnita en el imaginario europeo de la modernidad clásica.

El trabajo de Malena López Palmero titulado: Pocahontas entre dos mundos: el derrotero de la colonización de Virginia, en palabras de su autora: "analiza las transformaciones en la identidad de la joven indígena y las experiencias en el contacto con los ingleses, no tanto como evidencia del progreso colonial sino como imposiciones violentas de los colonos que, a una década de la expansión colonial, buscaban estabilizar el precario dominio de Virginia". De este modo, la propuesta de investigación centra su atención en las condiciones que permitieron el establecimiento del primer asentamiento colonial inglés en Virginia, como así también la dinámica político social alcanzada en esos años. El objetivo específico, es indagar las relaciones entabladas entre colonos e indígenas, entendiendo que las posibilidades de ocupación colonial estuvieron colindadas por las dinámicas de cooperación y de resistencia de los indígenas respecto a las tentativas de dominación de los ingleses.

Con estos fundamentos, los presentes estudios cumplen con el valioso aporte de transitar temas escasamente abordados por la historiografía argentina. En contraste con las fuentes propiamente dichas, que son accesibles en distintos repositorios, resulta bastante dificultoso encontrar bibliografía que estudie tanto los relatos de viajes reales o imaginarios, como la colonización de espacios por fuera de la América Española. Asimismo, no son habituales los trabajos acerca del impacto de la literatura de viajes en el imaginario y pensamiento 
filosófico francés de los siglos XVII y XVIII, contándose casi como excepciones los estudios de Enriqueta Bezián de Busquets en torno al libertinismo francés o aquellos de Rogelio Paredes alrededor de las relaciones existentes entre literatura ilustrada y experiencia de viaje. ${ }^{9}$

Descontamos que la calidad de los mismos servirá para contribuir a la temática en cuestión y tal vez, por qué no, puedan materializar el anhelo de nuevos trabajos de estos mismos colegas y también de otros, en busca de interlocutores igualmente cautivados con el mismo objeto. En definitiva y acaso cerrando el inicio de estas páginas, estos aportes incitan a reflexionar acerca de las potencialidades aún no agotadas de la literatura de viajes, y sobre todo a transitar a través de las hipótesis de trabajo planteadas, las sinuosidades y bifurcaciones a las que nos obliga el trabajo histórico e interdisciplinario a comienzos de este nuevo siglo.

9 BEZIÁN DE BUSQUETS, Enriqueta (compiladora), Otras caras del libertinismo francés (S. XVIII), UNT, Tucumán, 2008; BEZIÁN DE BUSQUETS, Enriqueta, Querellas, la République des Lettres T 5, UNT, Tucumán, 2008; PAREDES, Rogelio, "Viajes Occidentales: Crítica ilustrada y literatura oriental en Francia, Inglaterra y España (1721-1789)" en FERNÁNDEZ, Sandra, GELI, Patricio, y PIERINI, Margarita (editores), Derroteros del viaje en la cultura: mito, historia y discurso, Prohistoria Ediciones, Rosario, 2008. 